\title{
Effect of a kokumi peptide, $\gamma$-glutamyl-valyl-glycine, on the sensory characteristics of chicken consommé
}

\author{
Takashi Miyaki ${ }^{1}$, Hiroya Kawasaki ${ }^{2}$, Motonaka Kuroda ${ }^{1 *}$, Naohiro Miyamura ${ }^{1}$ and Tohru Kouda ${ }^{2}$
}

\begin{abstract}
Background: Recent studies have demonstrated that kokumi substances such as glutathione are perceived through the calcium-sensing receptor (CaSR). Screening by a CaSR assay and sensory evaluation have shown that $\gamma$-glutamyl-valyl-glycine ( $\gamma$-Glu-Val-Gly) is a potent kokumi peptide. In the present study, the sensory characteristics of chicken consommé with added $\gamma$-Glu-Val-Gly were investigated using descriptive analysis.

Results: Chicken consommé containing $Y$-Glu-Val-Gly had significantly stronger "umami" and "mouthfulness" (mouth-filling sensation) characteristics than the control sample at a 99\% confidence level and significantly stronger "mouth-coating" characteristic than controls at a 95\% confidence level.

Conclusions: These data suggest that a kokumi peptide, $\gamma$-Glu-Val-Gly, can enhance umami, mouthfulness, and mouth coating, implying that the application of this peptide could contribute to improving the flavor of chicken consommé.
\end{abstract}

Keywords: Chicken consommé, Kokumi, $\gamma$-Glutamyl-valyl-glycine, $\gamma$-Glu-Val-Gly, Sensory evaluation, Descriptive analysis

\section{Background}

Taste and aroma are important factors in determining the flavor of foods. Sweet, salty, sour, bitter, and umami comprise the five basic tastes with each taste being recognized by specific receptors and associated with particular transduction pathways. However, foods have sensory attributes that cannot be explained by aroma and the five basic tastes alone: texture, continuity, complexity, and mouthfulness. Ueda et al. investigated the flavoring effects of a diluted extract of garlic that enhanced continuity, mouthfulness, and thickness when added to an umami solution and attempted to isolate and identify the key compounds responsible for this effect [1]. Their study indicated that sulfur-containing compounds such as S-allyl-cysteine sulfoxide (alliin), S-methyl-cysteine sulfoxide, $\gamma$-glutamyl-allylcysteine, and glutathione ( $\gamma$-glutamyl-cysteinyl-glycine; GSH) led to this flavoring effect. These compounds have only a minimal flavor in water, but if added to an umami solution or other types of food, they can substantially

\footnotetext{
*Correspondence: motonaka_kuroda@ajinomoto.com

'Institute of Food Research and Technologies, Ajinomoto Co., Inc., 1-1

Suzuki-cho, Kawasaki-ku, Kawasaki, Kanagawa 210-8681, Japan

Full list of author information is available at the end of the article
}

enhance the thickness, continuity, and mouthfulness of the food to which they have been added [2]. They proposed that substances with these properties should be referred to as kokumi substances.

Recently, it was reported that kokumi substances such as GSH are perceived through the calciumsensing receptor (CaSR) in humans [3]. These studies confirmed that GSH can activate human CaSR, as can several $\gamma$-glutamyl peptides, including $\gamma$-Glu-Ala, $\gamma$-Glu-Val, $\gamma$-Glu-Cys, $\gamma$-Glu- $\alpha$-aminobutyryl-Gly (ophthalmic acid), and $\gamma$-Glu-Val-Gly. Furthermore, these compounds have been shown to possess the characteristics of kokumi substances, which modify the five basic tastes (especially sweet, salty, and umami) when added to basic taste solutions or food, even though they have no taste themselves at the concentrations tested [1,2,4-8]. The CaSR activity of these $\gamma$-glutamyl peptides has also been shown to be positively correlated with the sensory activity of kokumi substances, suggesting they are perceived through the CaSR in humans. Among these, $\gamma$-Glu-Val-Gly has been reported to be a potent kokumi peptide with a sensory activity 12.8-fold times greater than that of GSH [3]. Additionally, it has been reported that $\gamma$-Glu-Val-Gly 
was present in several foods such as scallops [9], fermented fish sauces [10], soy sauces [11], and fermented shrimp pastes [12]. Ohsu et al. also reported that adding 0.01\% $\gamma$-Glu-Val-Gly to $3.3 \%$ sucrose solution, $0.9 \% \mathrm{NaCl}$ solution, and $0.5 \%$ monosodium glutamate (MSG) solution significantly enhanced sweetness, saltiness, and umami, respectively [3]. They also reported that adding $0.002 \%$ $\gamma$-Glu-Val-Gly to chicken consommé prepared from commercial chicken consommé powder significantly enhanced thickness, continuity, and mouthfulness. In that report, sensory evaluation was undertaken with sensory attributes with reference to a method reported previously $[1,2]$. The sensory attributes used in these previous research works such as thickness, mouthfulness, and continuity were originally extracted using the sensory evaluation which compared the sensory profiles of various foods, mainly soups, with and without MSG [13]. Therefore, to clarify the sensory characteristics of food with added $\gamma$-Glu-Val-Gly, a more detailed study comparing the sensory attributes of food with and without this peptide has been needed.

In the present study, we aim to characterize the sensory properties of food with added $\gamma$-Glu-Val-Gly, through performing a descriptive analysis of chicken consommé containing the peptide.

\section{Results and discussion}

\section{Sensory attributes for chicken consommé}

During the project-specific orientation session, the panelists developed 17 attributes shown in Table 1. Regarding the attributes related to chicken flavor, since many words related to the chicken flavor were proposed during the project-specific orientation session, three attributes "total chicken/meaty flavour", "bones/marrow flavour", and "roasted flavour" were added to the list. Total chicken/meaty flavor was defined as the flavor intensity reminiscent of cooked chicken meat; bones/marrow flavor was defined as the character associated with chicken bones, particularly the marrow of chicken bones; and roasted flavor was defined as the total flavor intensity that is reminiscent of roasted chicken and/or vegetables. Additionally, because the coating sensation was well recognized when the panelists evaluated the chicken consommé with $\gamma$-Glu-Val-Gly during the project-specific panel orientation session, the attributes "mouth-coating" and "tongue-coating" were added to the list. "Mouth-coating" was defined as the degree to which there is a leftover residue, a slick, powdery, or fatty coating or film on the mouth that is difficult to clear. "Tongue-coating" was defined as the degree to which there is a leftover residue, a slick, powdery, or fatty coating or film on the tongue that is difficult to clear. Overall, the panelists defined the 17 sensory attributes for chicken consommé listed in Table 1 : nine taste and flavor attributes (total flavor, total chicken/ meaty flavor, chicken flavor, bones/marrow, roasted flavor, total vegetable flavor, richness, salty, and umami), seven texture/mouthfeel attributes (viscosity, mouthfulness, mouth coating, tongue coating, salivating, total trigeminal, and swelling perception of soft tissue), and one aftertaste (total aftertaste). The definitions of these sensory attributes and the references are shown in Table 2.

\section{Sensory characteristics of chicken consommé with added -Glu-Val-Gly}

The sensory characteristics of chicken consommé with or without $\gamma$-Glu-Val-Gly are shown in Table 2 and Figure 1. The addition of $\gamma$-Glu-Val-Gly at 5 ppm significantly enhanced the intensity of umami and mouthfulness at a $99 \%$ confidence level. Furthermore, the addition of this peptide significantly enhanced the intensity of mouth coating at a 95\% confidence level. Adding this peptide at $5 \mathrm{ppm}$ did not significantly change the intensity of the other attributes. A recent study has suggested that kokumi peptides such as GSH and $\gamma$-Glu-Val-Gly enhance the intensity of umami if they are added to $0.5 \%$ MSG solution [3], an observation consistent with the present study. Additionally, in the descriptive analysis, umami has been defined not only as the "taste of MSG" but also as "the mouth-filling sensation of compounds such as glutamates that is savoury, brothy, meaty, rich, full, and complex, which is common to many foods such as soy sauce, stocks, ripened cheese, shellfish, mushrooms, ripened tomatoes, cashews, and asparagus". Therefore, it appears that the enhancement of umami in chicken consommé includes the enhancement of sensations such as richness and complexity. The present results also suggest that $\gamma$-Glu-Val-Gly also enhanced mouthfulness. A previous study demonstrated that adding $\gamma$-Glu-Val-Gly at $20 \mathrm{ppm}$ to chicken soup significantly enhanced mouthfulness which is consistent with the present study [3]. Regarding other $\gamma$-glutamyl peptides, it has been reported that several kokumi $\gamma$-glutamyl peptides enhanced mouthfulness in food systems. Ueda et al. reported that the addition of GSH ( $\gamma$-Glu-Cys-Gly) enhanced the intensity of mouthfulness in model beef meat extract [2]. In addition, Ohsu et al. also reported that the addition of GSH enhanced the intensity of mouthfulness in chicken soup [3]. Furthermore, it has been reported that $\gamma$-glutamyl peptides such as $\gamma$-Glu-Val, $\gamma$-Glu-Leu, and $\gamma$-Glu-Cys-ßAla found as kokumi-active peptides in edible beans enhanced mouthfulness when they were added to chicken broth [5]. In addition, it has been reported that $\gamma$-Glu-Glu, $\gamma$-Glu-Gly, $\gamma$-Glu-His, $\gamma$-Glu-Gln, $\gamma$-Glu-Met, and $\gamma$-Glu-Leu were the key components which impart long-lasting mouthfulness of matured Gouda cheese. From these observations, it is demonstrated that many kokumi $\gamma$-glutamyl peptides enhance the intensity of mouthfulness. 
Table 1 Definition and reference samples for the descriptive attributes of chicken consommé

\begin{tabular}{|c|c|c|}
\hline Sensory attributes & Definitions & Reference samples and intensity \\
\hline Total flavor & $\begin{array}{l}\text { The total intensity of all of the flavors of the } \\
\text { sample including basic tastes }\end{array}$ & Kitchen Basics chicken broth (6) \\
\hline Total chicken/meaty flavor & $\begin{array}{l}\text { The flavor intensity reminiscent of cooked } \\
\text { chicken meat }\end{array}$ & Kitchen Basics chicken broth (5) \\
\hline Chicken flavor & $\begin{array}{l}\text { The flavor intensity reminiscent of cooked } \\
\text { chicken }\end{array}$ & Kitchen Basics chicken broth (5) \\
\hline Bones/marrow flavor & $\begin{array}{l}\text { The character associated with chicken bones, } \\
\text { particularly the marrow of chicken bones }\end{array}$ & NR \\
\hline Roasted flavor & $\begin{array}{l}\text { The total flavor intensity that is reminiscent } \\
\text { of roasted chicken and/or vegetables }\end{array}$ & Swanson's chicken broth (6) \\
\hline Total vegetable flavor & $\begin{array}{l}\text { The total flavor intensity of vegetables such } \\
\text { as carrots, green vegetables, and herbs in } \\
\text { the broth }\end{array}$ & Kitchen Basics chicken broth (5) \\
\hline Richness & $\begin{array}{l}\text { The degree to which the flavor characters of } \\
\text { the sample are harmonized, balanced, and } \\
\text { blend well together as opposed to being } \\
\text { spiky or striking out }\end{array}$ & NR \\
\hline Salty & $\begin{array}{l}\text { One of the basic taste, common to sodium } \\
\text { chloride }\end{array}$ & $\begin{array}{l}0.2 \% \text { sodium chloride in water (2) } 0.5 \% \text { sodium } \\
\text { chloride in water (5) } 0.2 \% \text { sodium chloride in } \\
\text { water (2) } 0.5 \% \text { sodium chloride in water (5) }\end{array}$ \\
\hline Umami & $\begin{array}{l}\text { One of the basic taste, common to MSG. } \\
\text { The taste and mouth-filling sensation of } \\
\text { compounds such as glutamates that is savory, } \\
\text { brothy, meaty, rich, full, and complex, common } \\
\text { to many foods such as soy sauce, stocks, } \\
\text { ripened cheese (especially parmesan), shellfish } \\
\text { (crab, lobster, scallops, clams), mushrooms } \\
\text { (especially porcini), ripe tomatoes, cashews, } \\
\text { and asparagus }\end{array}$ & $\begin{array}{l}\text { Kitchen Basics chicken broth (2) } 0.5 \% \text { MSG in } \\
\text { Kitchen Basics chicken broth (3.5) Kitchen Basics } \\
\text { chicken broth (2) 0.5\% MSG in Kitchen Basics } \\
\text { chicken broth (3.5) }\end{array}$ \\
\hline Viscosity & $\begin{array}{l}\text { The degree to which the samples are viscous } \\
\text { in the mouth from thin to thick }\end{array}$ & Water (1) Heavy whipping cream (6) \\
\hline Mouthfulness & $\begin{array}{l}\text { The perception that the sample fills the } \\
\text { whole mouth is blooming, or growing, a } \\
\text { full-bodied sensation when the sample is } \\
\text { held in the mouth }\end{array}$ & $\begin{array}{l}\text { Kitchen Basics chicken broth (1.5) 0.5\% MSG in } \\
\text { Kitchen Basics chicken broth (3) Kitchen Basics } \\
\text { chicken broth (1.5) 0.5\% MSG in Kitchen Basics } \\
\text { chicken broth (3) }\end{array}$ \\
\hline Mouth coating & $\begin{array}{l}\text { The degree to which there is a leftover } \\
\text { residue, a slick, powdery, or fatty coating or } \\
\text { film in the mouth that is difficult to clear }\end{array}$ & $\begin{array}{l}0.5 \% \text { MSG in water (4) Half and Half (5) } 0.5 \% \\
\text { MSG in water (4) Half and Half (5) }\end{array}$ \\
\hline Tongue coating & $\begin{array}{l}\text { The degree to which there is a leftover } \\
\text { residue, a slick, powdery, or fatty coating or } \\
\text { film on the tongue that is difficult to clear }\end{array}$ & $0.5 \%$ MSG in water (3) \\
\hline Total trigeminal & $\begin{array}{l}\text { The intensity of the total sensation, including } \\
\text { numbing, burning, tingling, or irritation, } \\
\text { impaired on the soft tissues of the oral } \\
\text { cavity, particularly the tongue }\end{array}$ & $\begin{array}{l}\text { Wintergreen breathsaver (NS) } 0.5 \% \text { MSG in } \\
\text { water (5) Wintergreen breathsaver (NS) } 0.5 \% \\
\text { MSG in water (5) }\end{array}$ \\
\hline Salivating & $\begin{array}{l}\text { The degree to which the sample caused a } \\
\text { perceived increase in salivation }\end{array}$ & NR \\
\hline Swelling of cheeks and lips & $\begin{array}{l}\text { The feeling of swelling of the soft tissue in } \\
\text { the oral cavity, specifically the cheeks and lips, } \\
\text { reminiscent of the perception of swelling } \\
\text { produced by antithetic treatments at a dental } \\
\text { office, but without a distinct numbing effect }\end{array}$ & $0.5 \%$ MSG in water (4) \\
\hline Total aftertaste & $\begin{array}{l}\text { The total aftertaste intensity after } 5 \mathrm{~s} \text { of all } \\
\text { flavor notes within the sample }\end{array}$ & NR \\
\hline
\end{tabular}


Table 2 Sensory characteristics of chicken consommé with added $\mathbf{\gamma}$-Glu-Val-Gly

\begin{tabular}{|c|c|c|c|c|c|c|}
\hline Sensory attributes & $\begin{array}{c}\text { Control } \\
\text { consomme }\end{array}$ & $\begin{array}{c}\text { Consomme with } \\
\text { Y-Glu-Val-Gly }\end{array}$ & $\begin{array}{l}\text { Changed } \\
\text { value }\end{array}$ & $\begin{array}{c}95 \% \text { confidence } \\
\text { interval }\end{array}$ & $\begin{array}{c}99 \% \text { confidence } \\
\text { interval }\end{array}$ & Significance \\
\hline Total flavor & $6.13 \pm 0.72$ & $6.31 \pm 0.68$ & $0.18 \pm 0.60$ & 0.28 & 0.36 & N.S. \\
\hline Total chicken/meaty flavor & $5.26 \pm 0.61$ & $5.41 \pm 0.59$ & $0.14 \pm 0.59$ & 0.27 & 0.36 & N.S. \\
\hline Chicken flavor & $4.82 \pm 0.55$ & $4.88 \pm 0.78$ & $0.06 \pm 0.69$ & 0.32 & 0.42 & N.S. \\
\hline Bones/marrow flavor & $2.42 \pm 0.85$ & $2.63 \pm 0.98$ & $0.21 \pm 1.14$ & 0.53 & 0.69 & N.S. \\
\hline Roasted flavor & $3.19 \pm 1.03$ & $3.12 \pm 1.03$ & $-0.07 \pm 0.82$ & 0.38 & 0.50 & N.S. \\
\hline Total vegetable flavor & $3.56 \pm 0.75$ & $3.78 \pm 0.81$ & $0.22 \pm 0.64$ & 0.30 & 0.39 & N.S. \\
\hline Richness & $4.01 \pm 0.81$ & $4.27 \pm 0.94$ & $0.27 \pm 0.79$ & 0.36 & 0.48 & N.S. \\
\hline Salty & $2.73 \pm 0.48$ & $2.87 \pm 0.73$ & $0.13 \pm 0.57$ & 0.26 & 0.35 & N.S. \\
\hline Umami & $2.84 \pm 0.65$ & $3.28 \pm 0.67$ & $0.43 \pm 0.66$ & 0.30 & 0.40 & $* *$ \\
\hline Viscosity & $2.06 \pm 0.65$ & $2.22 \pm 0.59$ & $0.16 \pm 0.40$ & 0.18 & 0.24 & N.S. \\
\hline Mouthfulness & $2.47 \pm 0.70$ & $2.92 \pm 0.73$ & $0.45 \pm 0.69$ & 0.32 & 0.42 & $* *$ \\
\hline Mouth coating & $2.67 \pm 0.66$ & $2.94 \pm 0.65$ & $0.27 \pm 0.56$ & 0.26 & 0.34 & * \\
\hline Tongue coating & $2.56 \pm 0.82$ & $2.72 \pm 0.82$ & $0.17 \pm 0.68$ & 0.32 & 0.42 & N.S. \\
\hline Salivating & $2.42 \pm 0.85$ & $2.58 \pm 0.83$ & $0.16 \pm 1.06$ & 0.49 & 0.64 & N.S. \\
\hline Total trigeminal & $2.76 \pm 0.87$ & $2.98 \pm 0.73$ & $0.23 \pm 0.84$ & 0.39 & 0.51 & N.S. \\
\hline Swelling perception of soft tissue & $2.78 \pm 0.79$ & $2.87 \pm 0.68$ & $0.09 \pm 0.76$ & 1.48 & 0.46 & N.S. \\
\hline Total aftertaste & $4.46 \pm 0.60$ & $4.54 \pm 0.66$ & $0.08 \pm 0.64$ & 0.29 & 0.38 & N.S. \\
\hline
\end{tabular}

Data was shown as means \pm standard errors.

N.S. not significant.

*Significant at a $95 \%$ confidence level, ${ }^{* *}$ significant at a $99 \%$ confidence level.

Interestingly, the present study has revealed that the addition of $\gamma$-Glu-Val-Gly at $5 \mathrm{ppm}$ significantly enhanced the intensity of mouth coating. It has been generally known that mouth-coating sensation is evoked by the addition of hydrocolloids such as xanthan gum and locust bean gum, carrageenan [14,15], and fat-containing food materials such as dairy fat emulsion [15]. However, several studies have reported that low-molecular-weight compounds enhanced the intensity of mouth coating. Dawid and Hofmann reported that 1,2-dithiolan-4-carboxylic acid 6-D-glucopyranoside ester exhibited a buttery mouth-coating sensation [16]. Additionally, the same research group demonstrated that polyphenolic compounds such as vanillin, vanillin-related compounds, americanin

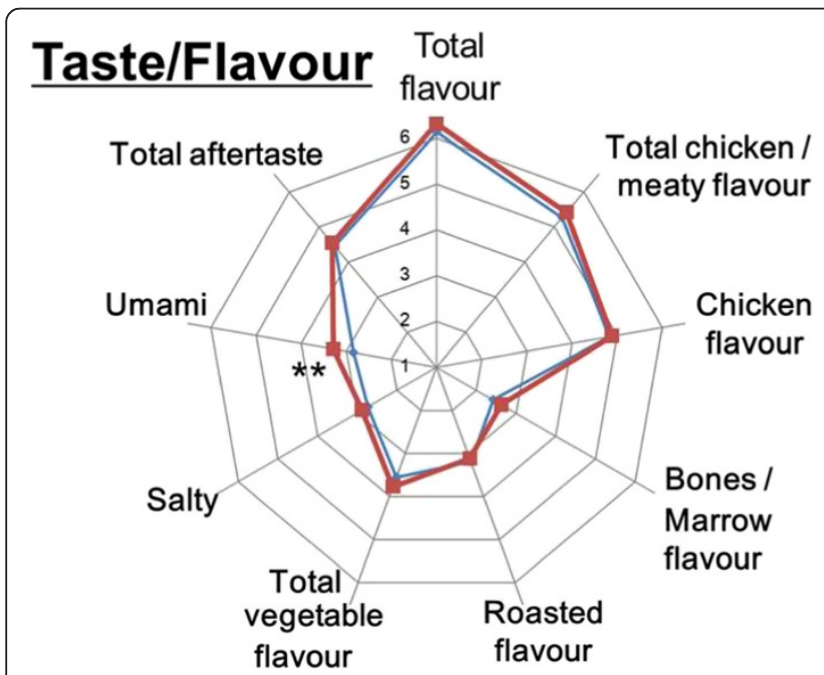

\section{Mouthfeel}

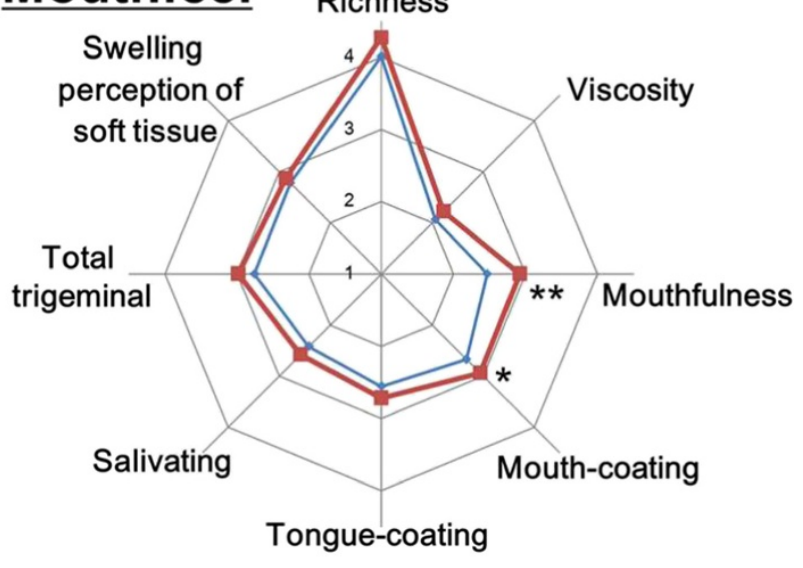

Figure 1 Graphical representation of the sensory characteristics of chicken consommé with added $\gamma$-Glu-Val-Gly. A blue fine line with diamond symbols indicates the mean scores of the control consommé. A red bold line with square symbols indicates the mean scores of the consommé with added 5 ppm of $\gamma$-Glu-Val-Gly. Asterisk denotes significance at a 95\% confidence level; double asterisks denote significance at a 99\% confidence level. 
A, and $4{ }^{\prime}, 6^{\prime}$-dihydroxy-3',5' -dimethoxy-[1,1' -biphenyl]3-carboxaldehyde from cured vanilla beans exhibited a velvety mouth-coating sensation [17]. Furthermore, it has been reported that the flavon-3-ol glycosides such as kaempferol glycosides, quercetin glycosides, myricetin glycosides, and apigenin glycoside from black tea induced a mouth-coating sensation [18]. Despite these observations, there have been no reports of a peptide which exhibited the mouth-coating sensation. Therefore, this is the first report which has demonstrated the mouth-coating effect of peptides. Although the viscosity of consommé did not change significantly by adding $5 \mathrm{ppm}$ of $\gamma$-Glu-Val-Gly (data not shown), an enhancement of the mouth-coating sensation was observed. The mechanism of this enhancement is interesting and should be clarified by further investigations.

In the present study, the addition of $\gamma$-glutamyl-valylglycine enhanced the intensity of umami, mouthfulness, and mouth coating. On the other hands, it has been reported that MSG, representative umami compound, also enhances the intensity of mouthfulness and the sensation related to mouth coating [13]. Previously, it has been demonstrated that $\gamma$-glutamyl-valyl-glycine enhanced the umami intensity when it was added to $0.3 \%$ MSG solution [3]. In addition, as shown in Table 3, the analysis of the chemical components revealed that chicken consommé contained glutamic acid $(51.1 \mathrm{mg} / \mathrm{dl})$ and IMP $(21.3 \mathrm{mg} / \mathrm{dl})$, and these concentrations of umami components were sufficient to evoke the umami sensation [13]. Therefore, it was considered that the enhancement of mouthfulness and mouth coating by $\gamma$-glutamyl-valyl-glycine was possibly caused by the enhancement of the function of the umami components. Regarding difference between the function of kokumi compounds and umami compounds, it was considered that the unique character of the kokumi compounds is that kokumi compounds have no taste themselves. Therefore, it can be assumed that kokumi compounds can enhance sensations like mouthfulness and continuity in sweet foods. In our recent study, it was observed that $\gamma$-glutamyl-valyl-glycine enhanced aftertaste, oiliness, and mouthfulness in reduced-fat peanut butter [19]. This result suggest that kokumi compounds can be used both in savory foods and sweet foods, while umami compounds can be used mainly in savory foods because of the characteristic umami taste. Further detailed studies are necessary to clarify the mechanism of the enhancement of the mouthfulness and mouth-coating sensation by $\gamma$-glutamyl-valyl-glycine.

The addition of $\gamma$-Glu-Val-Gly significantly enhanced the intensity of umami, mouthfulness, and mouth coating in chicken consommé. The results suggest that adding $\gamma$-Glu-Val-Gly can improve the flavor and mouthfeel of chicken consommé. To confirm this possibility, consumer preferences for chicken consommé with added
Table 3 Contents of free amino acids and 5'-nucleotide in chicken consomme

\begin{tabular}{lc}
\hline Component & Content $(\mathbf{m g} / \mathbf{d l})$ \\
\hline Amino acids & 74.9 \\
Taurine & 17.5 \\
Aspartic acid & 27.5 \\
Threonine & 20.3 \\
Serine & 51.1 \\
Glutamic acid & 15.8 \\
Glycine & 23.6 \\
Alanine & 10.2 \\
Valine & 4.7 \\
Methionine & 7.0 \\
Isoleucine & 12.4 \\
Leucine & 9.9 \\
Tyrosine & 8.0 \\
Phenylalanine & 17.0 \\
Lysine & 6.6 \\
Histidine & 23.7 \\
Arginine & 2.5 \\
Hydroxyproline & 10.0 \\
Proline & \\
5'-Nucleotide & N.D. \\
5'-GMP & \\
\hline N.D.not & \\
\hline
\end{tabular}

N.D. not detected.

$\gamma$-Glu-Val-Gly are now being investigated in our laboratory.

\section{Conclusions}

In the present study, the sensory characteristics of chicken consommé with 5.0 ppm added $\gamma$-Glu-Val-Gly were investigated using descriptive analysis. Chicken consommé containing $\gamma$-Glu-Val-Gly had significantly stronger "umami" and "mouthfulness" (mouth-filling sensation) characteristics than the control sample at a $99 \%$ confidence level and significantly stronger "mouth-coating" characteristic than the control at a 95\% confidence level. These data indicated that a kokumi peptide, $\gamma$ Glu-Val-Gly, can enhance umami, mouthfulness, and mouth coating in chicken consommé. From these results, it was suggested that the addition of $\gamma$-Glu-Val-Gly can improve the flavor and mouthfeel of chicken consommé.

\section{Methods}

\section{Preparation of $\gamma$-Glu-Val-Gly}

The $\gamma$-Glu-Val-Gly used in the present study was of food additive grade (FEMA-GRAS No. 4709; JECFA food 
flavoring No. 2123) obtained from Ajinomoto Co., Inc. (Tokyo, Japan) and was prepared by a chemical synthetic method reported previously [3].

\section{Preparation of chicken consommé}

The raw materials for chicken consommé are shown in Table 4. Minced chicken breast meat, minced chicken leg meat, and egg white were mixed. Then, minced chicken wing meat was added and mixed. The raw materials (except bouillon and water) were mixed in a 60-1 aluminum pot. Bouillon (Kisco Co. Ltd., Tokyo, Japan) diluted with the same volume of water was added and boiled at between $90^{\circ} \mathrm{C}$ and $95^{\circ} \mathrm{C}$ for $30 \mathrm{~min}$. After removing the meat, precipitate, and fat, the resulting chicken consommé was freeze-dried (freezing temperature, $-24^{\circ} \mathrm{C}$; vacuum $<13 \mathrm{~Pa}$; sample temperature, $<20^{\circ} \mathrm{C}$ ) using a Freeze Drier (RL-50 MB, Kyowa Vacuum Engineering Co. Ltd., Tokyo, Japan). For sensory evaluation, $5.6 \mathrm{~g}$ of the freeze-dried chicken consommé powder and $0.2 \mathrm{~g}$ of sodium chloride were dissolved in $100 \mathrm{ml}$ of distilled water and heated to $60^{\circ} \mathrm{C}$ and presented to the panelists. Approximately $90 \mathrm{ml}$ of consommé was served in foam cups coded with three-digit random numbers.

\section{Selection of the panel}

Eighteen female panelists participated in the sensory evaluation. The age of the panelists was $54.0 \pm 8.8$ (mean \pm standard deviation) years old. They all live in the San Francisco Bay Area, CA, USA. The screening of the panelists was conducted in three phases: phone screening of applicants, on-site acuity testing, and face-to-face interviews with advanced acuity testing.

Table 4 Raw materials for the chicken consommé

\begin{tabular}{lc}
\hline Materials & Weight (g) \\
\hline Chicken breast meat (minced) & $6,818.2$ \\
Chicken leg meat (minced) & $6,818.2$ \\
Chicken wing meat (minced) & $6,818.2$ \\
Egg white & $1,500.0$ \\
Fried onion & $1,687.5$ \\
Carrot & 562.5 \\
Celery & 375.0 \\
Tomato & $1,406.3$ \\
Tomato paste & 150.0 \\
Parsley & 18.8 \\
Black pepper & 5.6 \\
Bouillon (Kisco Co., Inc.) & $15,000.0$ \\
Water & $15,000.0$ \\
\hline
\end{tabular}

\section{Training of the panel}

\section{General panel training}

All of the panelists were broadly trained in sensory descriptive analysis to evaluate aromas, flavors, textures, and appearance across a wide range of consumer products. This training was conducted for approximately 3 days per week for 3 months, during which the panelists expanded their food sensory vocabularies, learned to use a 15-point scale to rate attribute intensities, and evaluated a wide variety of foods. For example, the sweetness intensity scale was anchored with several concentrations of sucrose in water and the intensity of "sweet aromatic" was anchored with several concentrations of vanilla in milk. The panelists-in-training refined their skills by participating in practice tests using many different types of products. After each test, they were given detailed feedback while retesting the products to help them improve their performance. After this training was complete, the panelists were registered as members of the Descriptive Panel of The National Food Laboratory and began to participate in the descriptive analysis of various kinds of foods.

\section{Ongoing panelist feedback}

Feedback was routinely provided during panel sessions to maintain and refine the evaluating ability of the panelists. Several times a month, the panelists were given faceto-face performance feedback to help them maintain their calibration. A panel leader tasted the products with the panelists as they reviewed their scores to highlight potential areas for improvement. Feedback was given both on discrimination among products and consistency between replications.

\section{Project-specific orientation sessions}

The objectives of the orientation training sessions were to understand the effect of $\gamma$-Glu-Val-Gly on chicken consommé to generate the list of sensory attributes for the evaluation sessions. This 2-h training session was conducted on the day before the sensory evaluation for the present study. During the session, panelists evaluated samples of chicken consommé with and without $\gamma$-GluVal-Gly to understand the effect of $\gamma$-Glu-Val-Gly. A panel leader led the group in discussion on the differences and similarities between the samples. They developed a list of sensory attributes that described the products' sensory characteristics, focusing on attributes believed to be influenced by $\gamma$-Glu-Val-Gly. Each sample was tested at least twice during this orientation session. During this training session, the panelists also developed new attributes such as "total chicken/meaty flavour", "bones/marrow flavour", "roasted flavour", "richness", "tongue-coating", and "salivating". Overall, the panelists defined the 17 sensory attributes listed in Table 2. The panelists practiced rating the samples 
on the list so that they were prepared to begin data collection.

\section{Project-specific panelist feedback}

Between each of the six data collection replications, panelists were given feedback about the samples they had evaluated. A panel leader led the group in brief discussions on the differences and similarities between the samples. Panelists were instructed to taste samples (with and without $5 \mathrm{ppm} \gamma$-Glu-Val-Gly) for training purposes during the discussions. After each feedback discussion, the panelists took a 10-min break before data collection for the next replication.

\section{Procedure for sensory evaluation}

For the evaluation of chicken consommé, panelists held the product in the mouth for $10 \mathrm{~s}$, expectorated, and then rated flavor, texture/mouthfeel, and aftertaste attributes. They then completed the rating for each attribute (samples with and without $5 \mathrm{ppm} \gamma$-Glu-Val-Gly) on a 15-point line scale. The sample serving order was balanced, with each sample being presented approximately an equal number of times in each position for each test. Two days of data collection were completed, each consisted of three replications. Feedback to the panelists was provided after each replication except the final replication. In total, six evaluations were conducted. In the present report, to investigate the effect of $\gamma$-Glu-Val-Gly on chicken consommé by an experimental protocol after a single feedback session, we report the result of the second replication of sensory evaluation data, which followed the first panelist feedback session on the first day of data collection. Human sensory analyses were conducted following the spirit of the Helsinki Declaration, and informed consent was obtained from all panelists. The experimental protocol was approved by the ethics board of the Institute of Food Sciences and Technologies, Ajinomoto.

\section{Analyses of free amino acids and 5'-nucleotides in chicken consommé}

Free amino acids were determined using a Model L-8800 amino acid analyzer (Hitachi Corp., Tokyo, Japan) with a lithium citrate buffer (PF-series for nonhydrolyzed amino acid analysis; Mitsubishi Chemical, Tokyo, Japan). The contents of $5^{\prime}$-nucleotides were determined by HPLC equipped with a Hitachi \#3013 column with detection at $254 \mathrm{~nm}$.

\section{Statistical analyses}

Statistical analyses were conducted using JMP version 9.0 (SAS Institute Inc., Cary, NC, USA). The data were collected as the means \pm standard deviation. Data were assessed by the paired $t$ test. The data was considered to be significant when the confidence level was more than $95 \%$.

\begin{abstract}
Abbreviations
Y-Glu-Val-Gly: -glutamyl-valyl-glycine; GSH: glutathione; CaSR: calciumsensing receptor; FEMA: Flavour and Extract Manufacturers Association; JECFA: The Joint FAO/WHO Expert Committee; MSG: monosodium glutamate; IMP: inosine monophosphate.
\end{abstract}

Competing interests

The authors declare that they have no competing interests.

\section{Authors' contributions}

MK, NM, and TK conceived the idea of this study. TM, MK, and NM designed the detail of experiments. TM and HK conducted the sample preparation and sensory evaluation. TM and MK conducted the analysis of sensory data and wrote the manuscript. All authors read and approved the final manuscript.

\section{Acknowledgements}

We sincerely thank Dr. Kiyoshi Miwa and Dr. Yuzuru Eto of Ajinomoto Co., Inc. for their encouragement and continued support of this work. We are grateful to Mr. Jiro Sakamoto of Ajinomoto North America LLC for his valuable discussion and assistance. We thank Ms. Sharon McEvoy, previously of the National Food Laboratory LLC, for her cooperation and a valuable discussion, and to the panelists who have participated on the sensory evaluation. We are grateful to Dr. Chinatsu Kasamatsu, Mr. Hiroaki Nagasaki, Mr. Toshifumi Imada, Mr. Takaho Tajima, Mr. Shuichi Jo, Mr. Keita Sasaki, and Ms. Takako Hirose of Ajinomoto Co., Inc. for their assistance. There is no funding in the present study.

\section{Author details}

${ }^{1}$ Institute of Food Research and Technologies, Ajinomoto Co., Inc., 1-1 Suzuki-cho, Kawasaki-ku, Kawasaki, Kanagawa 210-8681, Japan. ${ }^{2}$ Institute for Innovation, Ajinomoto Co., Inc., 1-1 Suzuki-cho, Kawasaki-ku, Kawasaki, Kanagawa 210-8681, Japan.

Received: 3 September 2014 Accepted: 1 December 2014 Published: 26 January 2015

References

1. Ueda Y, Sakaguchi M, Hirayama K, Miyajima R, Kimizuka A: Characteristic flavor constituents in water extract of garlic. Agric Biol Chem 1990, 54:163-169.

2. Ueda Y, Yonemitsu M, Tsubuku T, Sakaguchi M, Miyajima R: Flavor characteristics of glutathione in raw and cooked foodstuffs. Biosci Biotech Biochem 1997, 61:1977-1980.

3. Ohsu T, Amino Y, Nagasaki H, Yamanaka T, Takeshita S, Hatanaka T, Maruyama $Y$, Miyamura N, Eto $Y$ : Involvement of the calcium-sensing receptor in human taste perception. J Biol Chem 2010, 285:1016-1022.

4. Ueda Y, Tsubuku T, Miyajima R: Composition of sulfur-containing components in onion and their flavor characters. Biosci Biotech Biochem 1994, 61:108-110.

5. Dunkel A, Koster J, Hofmann T: Molecular and sensory characterization of Y-glutamyl peptides as key contributors to the kokumi taste of edible beans (Phaseolus vulgaris L.). J Agric Food Chem 2007, 55:6712-6719.

6. Toelstede S, Dunkel A, Hofmann T: A series of kokumi peptides impart the long-lasting mouthfulness of matured Gouda cheese. J Agric Food Chem 2009, 57:1440-1448

7. Toelstede S, Hofmann T: Kokumi-active glutamyl peptides in cheeses and their biogeneration by Penicillium roquefortii. J Agric Food Chem 2009, 57:3738-3748

8. Nishimura T, Egusa A: Classification of compounds enhancing "koku" to foods and the discovery of a novel "koku"-enhancing compound. Jpn J Taste Smell Res 2012, 19:167-176.

9. Kuroda M, Kato Y, Yamazaki J, Kageyama N, Mizukoshi T, Miyano H, Eto Y: Determination of $\gamma$-glutamyl-valyl-glycine in raw scallop and processed scallop products using high performance liquid chromatography-tandem mass spectrometry. Food Chem 2012, 134:1640-1644.

10. Kuroda M, Kato Y, Yamazaki J, Kai Y, Mizukoshi T, Miyano H, Eto Y: Determination and quantification of $\gamma$-glutamyl-valyl-glycine in commercial fish sauces. J Agric Food Chem 2012, 60:7291-7296. 
11. Kuroda M, Kato Y, Yamazaki J, Kai Y, Mizukoshi T, Miyano H, Eto Y: Determination and quantification of the kokumi peptide, $\gamma$-glutamyl-valyl-glycine, in commercial soy sauces. Food Chem 2013, 141:823-828.

12. Miyamura N, Kuroda M, Kato Y, Yamazaki J, Mizukoshi T, Miyano H, Eto Y: Determination and quantification of a kokumi peptide, $\gamma$-glutamyl-valylglycine, in fermented shrimp paste condiments. Food Sci Tech Res 2014, 20:699-703.

13. Yamaguchi S, Kimizuka A: Psychometric studies on the taste of monosodium glutamat. In Glutamic Acid: Advances in Biochemistry and Physiology. Edited by Filer $\sqcup \mathrm{Jr}$, Garattini S, Kare MR, Reynolds WA, Wurtman RJ. New York: Raven; 1979:35-54.

14. Arocas A, Sanz T, Varela P, Fiszman SM: Sensory properties determined by starch type in white sauces: effects of freeze/thaw and hydrocolloid addition. J Food Sci 2010, 75:S132-S140.

15. Flett KL, Duizer LM, Goff D: Perceived creaminess and viscosity of aggregated particles of casein micelles and k-carrageenan. J Food Sci 2010, 75:S255-S261.

16. Dawid C, Hofmann T: Identification of sensory-active phytochemicals in asparagus (Asparagus officinalis L.). J Agric Food Chem 2012,

60:11877-11888

17. Schwarz B, Hofmann T: Identification of novel orosensory active molecules in cured vanilla beans (Vanilla planifolia). J Agric and Food Chem 2009, 57:3729-3737.

18. Scharbert S, Holzmann N, Hofmann T: Identification of the astringent taste compounds in black tea infusions by combining instrumental analysis and human bioresponse. J Agric and Food Chem 2004, 52:3498-3508.

19. Miyamura N, Jo S, Kuroda M, Kouda T: Flavour improvement of reduced-fat peanut butter by addition of a kokumi peptide, $\gamma$-glutamyl-valyl-glycine. 2015 , in press.

doi:10.1186/2044-7248-4-17

Cite this article as: Miyaki et al:: Effect of a kokumi peptide, $\gamma$-glutamylvalyl-glycine, on the sensory characteristics of chicken consommé. Flavour 2015 4:17.

\section{Submit your next manuscript to BioMed Central and take full advantage of:}

- Convenient online submission

- Thorough peer review

- No space constraints or color figure charges

- Immediate publication on acceptance

- Inclusion in PubMed, CAS, Scopus and Google Scholar

- Research which is freely available for redistribution 